ARTIGOS

\title{
A matemática comercial e financeira nas escolas paroquiais luteranas do Rio Grande do Sul na primeira metade do século XX
}

\section{Commercial and financial mathematics in the Lutheran parochial schools of Rio Grande do Sul in the first half of the 20th century}

Malcus Cassiano Kuhn (i)

(i) Instituto Federal de Educação, Ciência e Tecnologia Sul-rio-grandense - IFSul, Lajeado, RS, Brasil, malcuskuhn@ifsul.edu.br.

(ii) Universidade Luterana do Brasil - ULBRA, Canoas, RS, Brasil, bayer@ulbra.br.

Resumo: $\mathrm{O}$ artigo discute como a matemática comercial e financeira era ensinada nas escolas paroquiais luteranas do Rio Grande do Sul, durante a primeira metade do século XX, por meio da análise da Segunda Aritmética e da Terceira Aritmética da série Concórdia, editadas pela Igreja Luterana para suas escolas. O aporte metodológico está fundamentado na história cultural e na análise de conteúdo. O Sínodo de Missouri, hoje Igreja Evangélica Luterana do Brasil, iniciou sua missão nas colônias alemãs gaúchas em 1900, fundando congregações religiosas e escolas paroquiais. Essas escolas estavam inseridas num projeto missionário e comunitário que buscava ensinar a língua materna, a matemática e os valores culturais, sociais e religiosos. A matemática comercial e financeira foi abordada de forma contextualizada com a realidade dos alunos, incentivando o desenvolvimento do pensamento proporcional, o cálculo correto de troco e de valores de dívidas, além do estudo de aplicações financeiras envolvendo juros simples.

Palavras-chave: porcentagem comercial, juros simples, série concórdia, ensino da Matemática, escolas paroquiais luteranas gaúchas 


\section{pro.posıções}

$e$-ISSN 1980-6248

http://dx.doi.org/10.1590/1980-6248-2016-0123

Abstract: The article discusses how commercial and financial mathematics was tanght in the Lutheran parochial schools of Rio Grande do Sul, during the first half of the 20th century, through the analysis of the Segunda Aritmética and of the Terceira Aritmética of the Concórdia series, edited by the Lutheran Church for their schools. The methodological support is grounded on cultural bistory and on content analysis. The Missouri Synod, currently the Evangelical Lutheran Church of Brazil, began its mission in the German colonies of Rio Grande do Sul in 1900, by founding religious congregations and parochial schools. These schools were inserted in a missionary and community project that sought to teach the mother tongue, mathematics, and cultural, social and religious values. Commercial and financial mathematics was approached in a contextualized manner in relation to the reality of the students, encouraging the development of the proportional thinking, of the correct calculation of return and debt values, and of the study of financial investments involving simple interest.

Keywords: commercial percentage, simple interest, Concórdia series, mathematics teaching, Lutheran parochial schools in Rio Grande do Sul

\section{Introdução}

O movimento migratório no Rio Grande do Sul - RS - tem sido objeto de investigações. No âmbito da História da Educação no estado gaúcho, os trabalhos de Arendt (2005), Kreutz (1991, 1994, 2008), Lemke (2001), Rambo (1994, 1996) e Weiduschadt (2007, 2012) são destaques. Na História da Educação Matemática no RS, destacam-se as pesquisas de Mauro (2005), Kreutz e Arendt (2007), Kuhn (2015), Silva (2014, 2015a, 2015b) e Wanderer (2007).

Este artigo tem o propósito de discutir, por meio da análise de livros de Aritmética editados para as escolas paroquiais luteranas do RS, como a matemática comercial e financeira era ali ensinada durante a primeira metade do século XX. Trata-se de um recorte de tese, complementado por pesquisas realizadas durante o estágio Pós-doutoral em um Programa de Pós-Graduação. Como a temática investigada se insere na História da Educação Matemática no estado gaúcho, com a análise de livros didáticos, busca-se na história cultural e na análise de conteúdo o suporte para discussão.

Conforme Chartier (1990), uma questão desafiadora para a história cultural é o uso que as pessoas fazem dos objetos que lhes são distribuídos ou dos modelos que lhes são impostos, uma vez que há sempre uma prática diferenciada na apropriação dos objetos colocados em circulação. Segundo o autor, pode-se dizer que a imprensa pedagógica, aqui representada pelas aritméticas da série Concórdia, foi um veículo para circulação de ideias que traduzem valores e 


\section{pro.posições}

$e$-ISSN 1980-6248

http://dx.doi.org/10.1590/1980-6248-2016-0123

comportamentos que se desejam ensinar - a ideologia luterana, sendo posta em convergência com outras estratégias políticas e culturais no RS.

Chervel (1990) considera importante o estudo histórico da cultura escolar para a compreensão dos elementos que participam da produção/elaboração/constituição dos saberes escolares e, em particular, da matemática escolar e sua história. Julia (2001) define a cultura escolar como um conjunto de normas que estabelecem conhecimentos a ensinar e condutas a inspirar, e um conjunto de práticas que permitem a transmissão desses conhecimentos e a incorporação desses comportamentos.

Uma investigação com enfoque na análise de conteúdo está sempre procurando um texto atrás de outro texto, um texto que não está aparente já na primeira leitura e que precisa de uma metodologia para ser desvendado. Bardin (2011) sugere três etapas para análise de conteúdo: a pré-análise em que se faz a escolha dos documentos e, a partir deles, a formulação de objetivos, de hipóteses e de indicadores para análise (unidades de análise); a exploração dos materiais por intermédio dos indicadores elaborados; e o tratamento dos resultados para interpretação das mensagens e das inferências.

A abordagem da matemática comercial e financeira nas escolas paroquiais luteranas do RS é realizada por meio de uma caracterização dessas escolas e de uma análise qualitativa das edições da Segunda Aritmética e da Terceira Aritmética, ambas da série Concórdia, editadas pela Igreja Evangélica Luterana do Brasil - IELB - para suas escolas paroquiais, na década de 1940. Este estudo está baseado num instrumento de análise de conteúdo construído com cinco unidades de análise $e^{1}$ e suas respectivas categorias, descrito em Kuhn (2015).

\footnotetext{
${ }^{1}$ As unidades de análise utilizadas para o estudo das aritméticas da série Concórdia foram: conteúdos (7 categorias), aspectos pedagógicos (8 categorias), processo de ensino e aprendizagem (6 categorias), recursos didáticos (5 categorias), linguagem e aspectos gráfico-editoriais (4 categorias).
} 


\section{pro.posıções}

$e$-ISSN 1980-6248

http://dx.doi.org/10.1590/1980-6248-2016-0123

\section{As escolas paroquiais luteranas do RS}

Com o início do trabalho missionário do Sínodo Evangélico Luterano Alemão de Missouri $^{2}$ no RS a partir de 1900, além das congregações luteranas, começaram a ser fundadas as escolas paroquiais. Para o Sínodo de Missouri, o sucesso da missão passava pela valorização da escola paroquial. Era necessário consolidar um campo religioso e fortalecê-lo investindo na escola, e também influenciar o campo familiar dos seus possíveis fiéis. "A escola paroquial se revelou como uma grande bênção para o bem e o desenvolvimento da Igreja Luterana. As congregações que mantinham escolas paroquiais, geralmente eram as melhores congregações" (Warth, 1979, p. 195). Por isso, os missourianos cuidaram não somente da formação de ministros como também de professores que atuassem de acordo com a filosofia educacional missouriana, contribuindo para que as escolas paroquiais atingissem seus objetivos como agência missionária e de educação geral.

As escolas paroquiais tinham uma responsabilidade para com a comunidade no sentido de, junto e com ela, promover o crescimento e o desenvolvimento pessoal de todos que a compunham, focando, principalmente, a cidadania. Se a escola formasse o ser humano com postura ética e moral exemplar, ele poderia promover transformações sólidas em seu contexto social e seria um verdadeiro colaborador na seara de Deus e para o governo do mundo. As escolas paroquiais luteranas são assim caracterizadas por Weiduschadt (2007):

As escolas eram organizadas de forma multisseriada. As turmas eram compostas de 20 a 40 alunos. $\mathrm{Na}$ maioria das vezes, o pastor da comunidade era, ao mesmo tempo, professor. As escolas funcionavam em forma comunitária, ou seja, a comunidade sustentava a estrutura física e mantinham o professor da escola. O prédio era muitas vezes o mesmo local do templo. A ligação entre a escola e a igreja era importante, porque logo no início da formação das comunidades o ensino doutrinário e pedagógico era ressaltado e sua suplementação implicava questões econômicas e culturais para a implementação. O projeto escolar dentro da comunidade religiosa era marcante, a orientação e a obrigação de os pais enviarem os filhos à escola eram quase obrigatórias, com sanções econômicas e morais, caso não concordassem. (pp. 166-168)

O Sínodo de Missouri também tinha uma preocupação acentuada em relação aos recursos didáticos usados nas escolas paroquiais, pois esse material era escasso e a dificuldade era grande em manter um ensino planificado e organizado. Assim, segundo Weiduschadt (2007),

\footnotetext{
${ }^{2}$ Em 1847, um grupo de imigrantes luteranos alemães da Saxônia fundou, no estado de Missouri (Estados Unidos), o Sínodo Evangélico Luterano Alemão de Missouri, Ohio e outros estados, atualmente Igreja Luterana - Sínodo de Missouri (Warth, 1979).
} 


\section{pro.posições}

$e$-ISSN 1980-6248

http://dx.doi.org/10.1590/1980-6248-2016-0123

“os livros usados nas escolas paroquiais e utilizados pelos alunos foram produzidos pelas instituições religiosas com objetivo de formar e moldar as condutas e as práticas ao fazer a escolarização das comunidades" (p.41). Dessa forma, por meio dos livros didáticos e dos periódicos, as escolas paroquiais luteranas conseguiram desenvolver uma educação integral cristã em todas as disciplinas, inclusive na Matemática. De acordo com Lemke (2001), o ensino da Palavra de Deus, através da Bíblia, ficava em primeiro lugar, e as demais disciplinas não eram menos prezadas, mas complementavam a educação para servir no mundo.

\section{0 ensino da Matemática nas escolas paroquiais luteranas do RS}

Para Kreutz (1994), o currículo das escolas paroquiais estava organizado de forma que as crianças aprendessem o essencial para o bom entrosamento na vida das comunidades rurais, sob o aspecto tanto religioso e social quanto do trabalho. Havia preocupação em construir o conhecimento vinculado à realidade do aluno. Segundo Schubring (2003), nos primeiros períodos de colonização, para o ensino da Matemática foram usados livros trazidos da Alemanha ou recebidos como doações. Os livros que passaram a ser produzidos no sul do Brasil, no final do século XIX, seguiram as tendências da metodologia da Matemática na Alemanha, porém, adapatando-se à realidade dos colonos no Brasil. Por isso, os teuto-brasileiros tomavam cuidados quanto à elaboração e à impressão de material didático adequado à realidade local e regional.

De acordo com Weiduschadt (2007), o ensino da Matemática era muito valorizado nas escolas paroquiais luteranas do RS:

Pela necessidade do trabalho e para ser usada na vida cotidiana a matemática era muito valorizada. $\mathrm{O}$ ensino da matemática era difundido, pois a criança necessitava ter domínio desse conhecimento para poder usar no dia a dia. Aprendiam os conceitos elementares e práticos da matemática. Em relação à economia eles precisavam aprender fundamentos básicos de matemática para que fosse permitido negociar seus produtos agrícolas. (p. 195)

Com relação ao ensino da Matemática nas escolas paroquiais luteranas, Lindemann (1888) afirma que 


\section{pro.posições}

$e$-ISSN 1980-6248

http://dx.doi.org/10.1590/1980-6248-2016-0123

nas classes iniciais, não importa muito a aritmética escrita, mas que as crianças entendam intuitivamente a ideia dos números e do sistema decimal. Nos primeiros anos de escola será suficiente que as crianças compreendam os números de 1 a 1000 corretamente, saibam ler e escrever os números e executar os cálculos básicos envolvendo as quatro operações. Nos anos seguintes, devem aprender as quatro operações com todos os números e também os números decimais. Mais adiante, aprendem as frações comuns, unidades de medida, cálculos com preços e percentagem e a solução de tarefas geométricas simples. O treino e memorização de tabelas com unidades de medida, de pesos e moedas devem ser realizadas mais no final da escolarização. [tradução nossa]. (p. 51)

Rambo (1994) acrescenta que o cálculo aritmético era um recurso prático indispensável ao indivíduo atuante numa comunidade qualquer ou numa determinada sociedade.

A familiaridade e o manejo do cálculo mental, oral e escrito, ao menos até o nível de juros simples e compostos, da regra de três e outros, representava o mínimo de ferramental, indispensável para a solução dos múltiplos problemas do dia a dia. O colono tinha que saber controlar com certa exatidão suas receitas e despesas. Era preciso fazer previsões mais ou menos confiáveis. A correta administração do orçamento familiar e o gerenciamento da produção da sua propriedade rural requeriam algo além do que uma simples familiaridade abstrata com relações numéricas. Lidando com a terra, era obrigado a saber fazer cálculos aproximados de superfície. Esse fato obrigava a assimilar noções básicas de geometria, além de conhecimentos corretos do sistema métrico. Lidando diariamente com dinheiro, inclusive com empréstimos na rede de agências das caixas rurais, exigia-se habilitação no manejo do cálculo de juros simples e compostos. O trabalho com madeira, com grãos, com banha só podia ser confiável com o domínio dos rudimentos do cálculo volumétrico nas suas mais diversas formas. A familiaridade com os diversos sistemas métricos significava um pré-requisito insubstituível. Um dos aspectos mais positivos no aprendizado do cálculo consistia na sua natureza eminentemente prática. (pp. 154-155)

Sommer (1984) reforça que "já no quarto ano, ensinava-se regra de três, taxa de descontos, juros, cálculos de área e volume, tudo ilustrado com exemplos práticos da vida cotidiana dos colonos e dos comerciantes" (p. 70).

Registra-se que os primeiros 30 anos de existência das escolas paroquiais luteranas no RS foram marcados pela carência de materiais didáticos e pela progressiva adoção dos 4 manuais de Büchler, tanto em alemão, quanto em português, para as aulas de Matemática. No periódico Unsere Schule3 (1933), afirma-se "que os livros de aritmética de Büchler (editora Rotermund) ${ }^{4}$ são

\footnotetext{
${ }^{3} \mathrm{Na}$ década de 1930, a IELB começou a publicar um periódico pedagógico dirigido às escolas paroquiais, chamado Unsere Schule (Nossa Escola).

4 A editora Rotermund, de São Leopoldo editava e publicava o material didático relacionado ao Sínodo RioGrandense (Igreja Evangélica de Confissão Luterana no Brasil - IECLB).
} 


\section{pro.posıções}

$e$-ISSN 1980-6248

http://dx.doi.org/10.1590/1980-6248-2016-0123

usados na maioria das nossas escolas e que a mesma editora lançou recentemente um novo manual: meu livro de contas, por W. Nast e L. Tochtrop”[tradução nossa] (p. 6).

Porém, na mesma edição, esse manual é analisado criticamente, apontando a necessidade de livros com princípios missourianos morais e educacionais, com uso de princípios pedagógicos modernos e adaptados às condições nacionais.

Por isso, o Sínodo de Missouri começou a produzir seus próprios livros de Aritmética na década de 1930. No periódico Unsere Schule, faz-se referência aos novos livros de aritmética: "o Sínodo decidiu que será editado neste ano um trabalho completo de aritmética. Os professores Frederico Strelow, Albert Brückmann e Max Öhlwein foram contratados para realizar o trabalho" [tradução nossa] (Unsere Schule, 1934, p. 14). Este trabalho completo de Aritmética foi a série Ordem e Progresso, pois, em edições posteriores, o mesmo periódico fez divulgação da Primeira Aritmética e da Segunda Aritmética dessa série.

A edição e a publicação do material didático específico para as escolas paroquiais luteranas gaúchas, com base em princípios morais e educacionais idealizados pela IELB, foram realizadas pela Casa Publicadora Concórdia ${ }^{5}$, de Porto Alegre/RS. Para as aulas de Matemática, foram publicadas duas séries: a série Ordem e Progresso, lançada na década de 1930, pela divulgação feita no periódico Unsere Schule; e a série Concórdia, lançada na década de 1940. Cada série é composta pela Primeira Aritmética, Segunda Aritmética e Terceira Aritmética.

A partir do instrumento de análise de conteúdo construído com cinco unidades de análise e suas respectivas categorias, fundamentado em Bardin (2011) e descrito em Kuhn (2015), realiza-se a análise da Segunda Aritmética (1948) e da Terceira Aritmética (1949), ambas da série Concórdia, nas quais se encontraram registros da matemática comercial e financeira. Embora as duas aritméticas não possuam autoria declarada, acredita-se que os autores dessas obras tenham sido professores das escolas paroquiais luteranas, devido a referências feitas no periódico Unsere Schule sobre os responsáveis pela elaboração dos livros de Aritmética.

\footnotetext{
${ }^{5}$ Fundada em 1923, atuava na edição de livros e de periódicos relacionados à literatura religiosa e escolar da IELB. Foi a primeira e a única redatora da IELB, existente até os dias atuais. Antes de sua fundação, os livros e os periódicos eram impressos pela Concordia Publishing House nos Estados Unidos e enviados ao Brasil.
} 


\section{pro.posıções}

$e$-ISSN 1980-6248

\section{Quadro 2 - Escrituração}

\begin{tabular}{|c|c|c|c|c|c|c|c|}
\hline \multicolumn{4}{|c|}{ Entrada } & \multicolumn{4}{|c|}{ Saída } \\
\hline Março & 3 & 5 sacos de milho & Cr $\$ 60,00$ & Março & 5 & Fazendas & Cr $\$ 38,00$ \\
\hline Março & 9 & $90 \mathrm{~kg}$ de banha & $\operatorname{Cr} \$ 45,00$ & Março & 11 & Impostos & Cr\$87,50 \\
\hline Março & 17 & 3 sacos de amendoim & $\mathrm{Cr} \$ 24,00$ & Março & 25 & Jornal & $\operatorname{Cr} \$ 12,50$ \\
\hline Março & 21 & 4 sacos de feijão & $\mathrm{Cr} \$ 72,00$ & Março & 28 & Farmácia & $\mathrm{Cr} \$ 25,00$ \\
\hline Março & 28 & 2 sacos de batata & Cr\$ 18,00 & Março & 31 & Igreja & $\operatorname{Cr} \$ 20,00$ \\
\hline $\begin{array}{l}\text { 1) } \\
\text { 2) } \\
\text { 3) }\end{array}$ & $\begin{array}{l}\text { Qua } \\
\text { Qua } \\
\text { Que }\end{array}$ & obrou no fim do mês? & $\begin{array}{l}\text { e março? } \\
\text { narço? }\end{array}$ & & & & \\
\hline
\end{tabular}

Fonte: Série Concórdia (1948, p. 47).

O exercício de escrituração apresentado no Quadro 2 traz informações sobre as entradas e as saídas no mês de março, provavelmente relacionadas ao orçamento familiar de um agricultor. A partir dessas informações se propõe o cálculo do total de entradas, do total de saídas e do saldo final, envolvendo, de forma contextualizada, frações decimais. Esse tipo de exercício tinha sua importância, pois, de acordo com Rambo (1994), se esperava que a escola desse suporte para que os futuros colonos realizassem a correta administração do orçamento familiar e o gerenciamento da produção da sua propriedade rural.

No Quadro 3, observa-se um exercício relacionado a uma nota de compra

\section{Quadro 3 - Nota de compra}

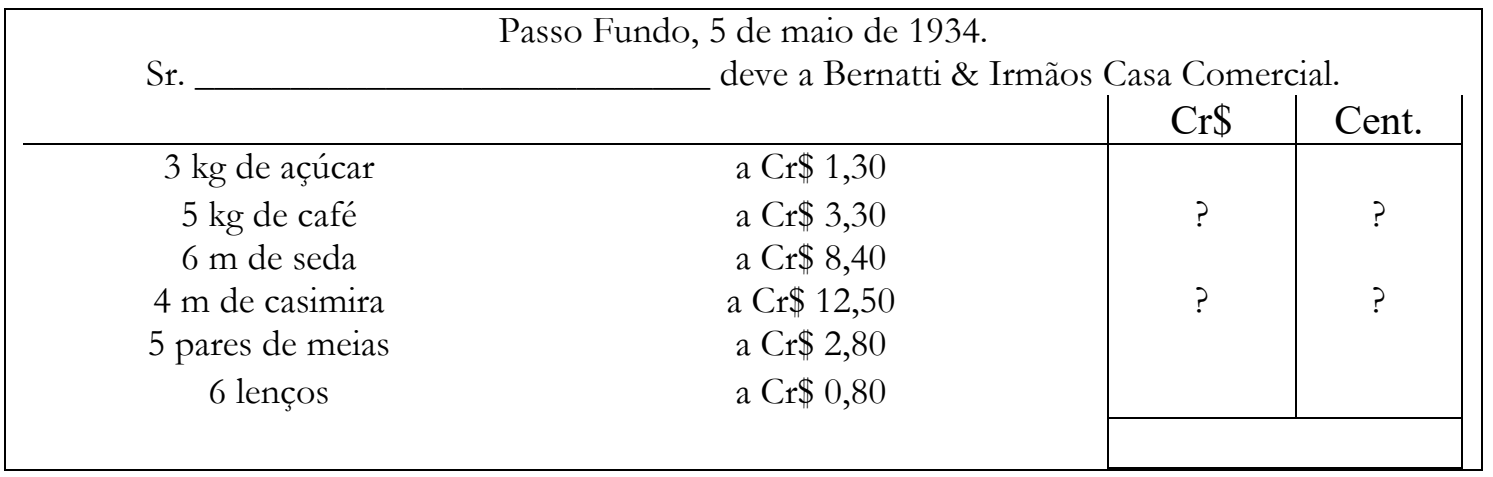

Fonte: Série Concórdia (1948, p. 64).

O exercício mostrado no Quadro 3 propõe o preenchimento correto de uma nota de compra de mercadorias numa casa comercial. Era necessário que o aluno calculasse o gasto total na compra de cada mercadoria através da multiplicação de um número inteiro por uma fração decimal e depois, por meio de uma soma de frações decimais, determinasse o valor total da nota. 


\section{pro.posıções}

$e$-ISSN 1980-6248

http://dx.doi.org/10.1590/1980-6248-2016-0123

O desenvolvimento deste tipo de exercício com os alunos das escolas paroquiais luteranas está relacionado com o fato de que, segundo Dreher (1999), cada picada ${ }^{6}$ abrigava uma casa comercial, para a qual eram vendidos os excedentes de produção e adquiridos os bens não produzidos na comunidade.

No Quadro 4, a partir de uma fatura, propõe-se a determinação do preço de compra e de venda de cada artigo.

\section{Quadro 4-Compras e vendas}

1) Um negociante recebeu a seguinte fatura:

10 rolos de arame farpado $\mathrm{Cr} \$ 230,00$

10 rolos de arame liso $\quad$ Cr $\$ 180,00$

10 machados $\quad$ Cr\$ $\$ 60,00$

10 foices Cr $\$ 50,00$

Qual é o preço de compra de cada artigo?

Qual é o preço de venda, querendo lucrar em cada artigo a décima parte do preço da compra?

Fonte: Série Concórdia (1948, p. 79).

O excerto mostrado no Quadro 4 traz os dados de uma fatura de compra realizada por um negociante. Propõe-se determinar o preço de compra de cada artigo e o de venda, sabendo que o lucro em cada artigo deve ser a décima parte do preço pago na compra. É uma atividade em que está subentendida a ideia de calcular o preço de venda com $10 \%$ de lucro sobre o preço de compra de cada artigo. Conforme Lindemann (1888), as tarefas escolares deveriam levar em conta a vida prática, pois, no futuro, a criança precisaria realizar cálculos de preços, determinar o lucro ou o prejuízo em transações comerciais. Ressalta-se que esta edição traz outras propostas de ensino, envolvendo faturas ou notas de compras no contexto das colônias alemãs gaúchas.

A Terceira Aritmética da série Concórdia tem 143 páginas e apresenta como principais unidades de estudo: frações decimais e sistema métrico; frações ordinárias; regra de três; porcentagem; porcentagem comercial; juros; razão e proporção; geometria prática.

$\mathrm{Na}$ edição da Terceira Aritmética se encontraram mais registros relacionados com a matemática comercial e financeira. Identificaram-se excertos associados com operações

\footnotetext{
${ }^{6}$ Organização social na qual se encontravam o templo (católico ou luterano, as confissões religiosas às quais pertenciam os imigrantes alemães), a escola, o cemitério, a residência do professor ou do padre/pastor, o salão de festas comunitárias e a casa comercial (Dreher, 1999).
} 


\section{pro.posıções}

$e$-ISSN 1980-6248

http://dx.doi.org/10.1590/1980-6248-2016-0123

comerciais, porcentagem comercial, juros e regra de sociedade. No Quadro 5, apresenta-se um problema relacionado com transações comerciais, envolvendo operações com frações decimais.

Quadro 5 - Problema sobre transações comerciais

\begin{tabular}{|c|c|}
\hline 1) Um freguês vende: & Compra: \\
\hline $6,700 \mathrm{~kg}$ de manteiga a $\operatorname{Cr} \$ 4,50$ & $5,50 \mathrm{~m}$ de brim a $\operatorname{Cr} \$ 3,80$ \\
\hline $18,000 \mathrm{~kg}$ de banha a $\operatorname{Cr} \$ 1,85$ & $8,50 \mathrm{~m}$ de morim a $\operatorname{Cr} \$ 2,30$ \\
\hline $7,800 \mathrm{~kg}$ de linguiça a $\mathrm{Cr} \$ 2,10$ & $3,50 \mathrm{~m}$ de tricolina a $\operatorname{Cr} \$ 4,60$ \\
\hline $3 \frac{1}{2}$ dúzias de ovos a $\operatorname{Cr} \$ 0,80$ & $4 \mathrm{~kg}$ de açúcar a Cr\$1,30 \\
\hline $5,700 \mathrm{~kg}$ de toucinho a $\operatorname{Cr} \$ 1,90$ & 2 rolos de arame a $\mathrm{Cr} \$ 24,50$ \\
\hline 3 sacos de feijão a $\operatorname{Cr} \$ 17,50$ & 2 pacotes de prego a $\operatorname{Cr} \$ 4,50$ \\
\hline 14 galinhas a $\mathrm{Cr} \$ 1,90$ & \\
\hline $3,400 \mathrm{~kg}$ de queijo a $\operatorname{Cr} \$ 2,30$ & Quanto dinheiro lhe sobra? \\
\hline
\end{tabular}

Fonte: Série Concórdia (1949, p. 18).

O excerto descrito no Quadro 5 se refere a uma operação comercial comum nas colônias alemãs do RS. Desde as origens da colonização alemã no RS, as trocas de mercadorias se fizeram por permuta. A universalidade e a perenidade do sistema, nascido da ausência de capital mobiliário e de moeda circulante, eram características da colônia $\mathrm{O}$ colono trazia seu excedente de produção para a venda na casa comercial, da qual levava sua contrapartida em artigos fabricados ou em gêneros alimentícios. Roche (1969) revela, "trazia um saco de feijão, uma lata de banha ou uma dúzia de ovos se apenas precisava de pouca coisa; trazia mais se previa grandes compras" (p. 411). As trocas se fizeram, de início, à vista. Depois, certos comerciantes abriram contas correntes a seus fregueses acreditados. "Levavam, na receita, os ovos ou o toucinho, e, na despesa, o sal, o açúcar, o café e os tecidos, era já um embrião de crédito" (Roche, 1969, p. 412). Observa-se que o problema apresenta oito produtos levados por um freguês para a casa comercial (venda) e seis produtos que ele compra, com os seus respectivos preços unitários. Era preciso calcular o valor correspondente a cada mercadoria em função da quantidade vendida ou comprada, o valor total de venda e o valor total de compra, para, então, determinar quanto dinheiro sobrava para o freguês.

$\mathrm{Na}$ quinta unidade de estudo da Terceira Aritmética, propõe-se a "porcentagem comercial": peso bruto, tara e peso líquido; lucros e perdas; compras e vendas; descontos. No Quadro 6, ilustra-se a proposta de estudo para peso bruto, tara e peso líquido. 


\section{pro.posıções}

$e$-ISSN 1980-6248

http://dx.doi.org/10.1590/1980-6248-2016-0123

\section{Quadro 6 - Peso bruto, tara e peso líquido}

Exemplo) Uma caixa de sabão pesa $28,500 \mathrm{~kg}$. A caixa vazia pesa $2,500 \mathrm{~kg}$.

$28,500 \mathrm{~kg}$--- peso bruto ou total

$2,500 \mathrm{~kg}---$ tara

$26,000 \mathrm{~kg}---$ peso líquido

1) 10 sacos de arroz pesaram $600 \mathrm{~kg}$. A tara representou 4\%. Quanto foi pago pelo arroz, se $100 \mathrm{~kg}$ do peso líquido custaram $\mathrm{Cr} \$ 55,00$ ?

2) Uma caixa com sabão pesa $28,500 \mathrm{~kg}$ e custa $\mathrm{Cr} \$ 26,50$. A tara atinge $7 \% .1 \mathrm{~kg}$ do peso líquido será vendido por Cr\$1,60. Qual o lucro?

Fonte: Série Concórdia (1949, pp. 91-93).

Após desenvolver a ideia de porcentagem, explorar cálculos sobre porcentagens, cálculo da taxa e cálculo do valor nominal, a Terceira Aritmética apresenta o estudo da porcentagem comercial. Inicialmente, desenvolve-se a ideia de peso bruto ou total, tara e peso líquido, a partir de uma caixa de sabão, conforme observado no Quadro 6. Exploram-se também cálculos percentuais em problemas relacionados com diferentes contextos de operações comerciais, associados aos conceitos de peso bruto, de tara e de peso líquido. A proposta de estudo desses conceitos reforça o desenvolvimento da matemática em seus aspectos informativo e utilitário para os alunos das escolas paroquiais luteranas gaúchas do século passado.

No Quadro 7, apresenta-se a proposta de estudo para lucros e perdas, encontrada na Terceira Aritmética. 


\section{pro.posıções}

$e$-ISSN 1980-6248

\section{Quadro 7 - Lucros e perdas}

No preço de mercadoria entram a importância da fatura e outras despesas, tais como frete, imposto de alfândega, carretos, etc..

Importância da fatura + despesas $=$ preço de compra

Ao preço de compra acrescentamos ainda as despesas do negócio, tais como: aluguéis, salários, impostos, luz, etc..

Preço de compra + despesas $=$ preço de custo

Ao preço de custo acrescentam-se ainda o lucro.

Preço de custo + lucro $=$ preço de venda

Exemplo 1) Um fogão de ferro, que custou Cr\$500,00, foi vendido com $12 \%$ de lucro.

Calcular o preço de venda.

Solução: Cr\$ 100 deram um lucro de Cr\$ 12

Cr\$ 1 deu um lucro de Cr\$ $\$ 12 \div 100$

$\operatorname{Cr} \$ 500$ deram um lucro de $\operatorname{Cr} \$ 12 \div 100 \times 500=\frac{12 \times 500}{100}=\operatorname{Cr} \$ 60$

Preço de compra .......... Cr\$ 500

lucro ......... Cr $\$ 60$

Preço de venda ........... Cr $\$ 560 \quad$ Cr $\$ 500+12 \%=\operatorname{Cr} \$ 560$

Exemplo 2) Uma máquina, que custou Cr\$ 800,00, foi vendida com 7\% de prejuízo. Calcular o preço de venda.

Solução: Cr\$100 deram um prejuízo de Cr\$ 7

Cr\$ 1 deu um prejuízo de $\operatorname{Cr} \$ 7 \div 100$

Cr\$ 800 deram um prejuízo de $\operatorname{Cr} \$ 7 \div 100 \times 800=\frac{7 \times 800}{100}=\operatorname{Cr} \$ 56$

Preço de compra Cr\$ 800

prejuízo .......... Cr\$ 56

Preço de venda ............ Cr $\$ 744 \quad$ Cr $\$ 800-7 \%=\mathrm{Cr} \$ 744$

Exemplo 3) Uma máquina foi comprada por Cr\$ 900,00 e vendida por Cr\$1.008,00. De quantos $\%$ foi o lucro?

Solução: Preço de venda

Cr\$1.008,00

Preço de compra ........ Cr $\$ 900,00$

Cr\$ 900 deram um lucro de Cr\$108

Cr\$ 1 deu um lucro de Cr\$ $108 \div 900$

Cr\$100 deram um lucro de Cr\$108 $\$ 900 \times 100=\frac{108 \times 100}{900}=\operatorname{Cr} \$ 12$

O lucro é de $12 \%$.

Exemplo 4) Uma casa que foi comprada por Cr\$5.000,00, foi vendida por Cr\$4.300,00. De quantos $\%$ foi o prejuízo?

Solução: Preço de compra

Preço de venda ............ Cr $\$ 4.300,00$

prejuízo

Cr\$ 700,00

Em Cr\$ 5.000 o prejuízo é de Cr\$ 700

Em Cr\$ 1 o prejuízo é de Cr\$ $700 \div 5000$

Em Cr\$ 100 o prejuízo é de Cr\$ $700 \div 5000 \times 100=\frac{700 \times 100}{5000}=\operatorname{Cr} \$ 14$

O prejuízo foi de $14 \%$.

1) Um vendedor de milho compra 150 sacos de milho por $\operatorname{Cr} \$ 1.275,00$. Vende a mercadoria com um lucro de $33 \frac{1}{3} \%$. Por quanto vende o saco?

2) Um vendedor de banha comprou $580 \mathrm{~kg}$ de banha a $\mathrm{Cr} \$ 2,80 \mathrm{o} \mathrm{kg}$. O preço baixou de $25 \%$. Calcular o prejuízo.

Fonte: Série Concórdia (1949, pp. 93-95). 


\section{pro.posições}

$e$-ISSN 1980-6248

http://dx.doi.org/10.1590/1980-6248-2016-0123

A aplicação da porcentagem em situações envolvendo lucros ou perdas é introduzida através de uma sistematização sobre preço de compra, preço de custo e preço de venda. Em seguida, apresentam-se exemplos relacionados com lucros ou perdas. Verifica-se que, nos dois primeiros exemplos, se calcula o lucro ou o prejuízo a partir do preço de compra e da taxa percentual sobre ele na operação de venda. Na resolução, observa-se a tomada da taxa percentual em relação a Cr\$100,00 e o desenvolvimento do pensamento proporcional, fazendose a dedução da multiplicidade $(\operatorname{Cr} \$ 100,00)$ para a unidade $(\operatorname{Cr} \$ 1,00)$ e da unidade para a multiplicidade (preço de compra), valendo-se da divisão e da multiplicação como operações inversas, no cálculo do preço de venda com lucro ou prejuízo.

Nos outros dois exemplos, calcula-se a taxa percentual de lucro ou a taxa percentual de prejuízo a partir do preço original e do lucro ou do prejuízo sobre ele na operação de venda. $\mathrm{Na}$ resolução, observa-se o desenvolvimento do pensamento proporcional, fazendo-se a dedução da multiplicidade (preço original) para a unidade $(\operatorname{Cr} \$ 1,00)$ e da unidade para a multiplicidade (Cr\$ 100,00), valendo-se da divisão e da multiplicação como operações inversas, para determinação da taxa percentual em relação a Cr\$100,00 na operação de venda com lucro ou prejuízo. No exemplo 4, com Cr\$100,00 lucraram-se Cr\$12,00, logo, a taxa percentual de lucro foi de $12 \%$.

Ressalta-se que nos exemplos desenvolvidos ficam subentendidas as ideias de acréscimo (ou taxa de aumento) nas operações comerciais envolvendo lucro, e de desconto (ou taxa de desconto) nas operações comerciais que resultam em prejuízo. O livro também propõe a resolução de problemas envolvendo lucros ou perdas em diferentes contextos comerciais da realidade dos alunos das escolas paroquiais luteranas gaúchas, destacando-se o uso de números mistos para representação de taxas percentuais não inteiras, como observado no problema 1 do Quadro 7.

A Terceira Aritmética ainda propõe o estudo das operações de compra e de venda a partir do preço de venda, como mostra o Quadro 8. 


\section{pro.posıções}

$e$-ISSN 1980-6248

\section{Quadro 8-Compras e vendas}

Exemplo) Um negociante vendeu mercadorias no valor de Cr\$3.600,00. O lucro importou em $20 \%$. Qual o preço de compra?

Solução: Cr\$120 de venda correspondem a Cr\$100 de compra

Cr\$ 1 de venda corresponde a $100 \div 120$

Cr $\$ 3.600$ de venda correspondem a $100 \div 120 \times 3600=\frac{100 \times 3600}{120}=3000$

O preço de compra era de $\operatorname{Cr} \$ 3.000,00$.

1) Em consequência da baixa dos preços 150 sacos de arroz foram vendidos por Cr $\$ 4.500,00$ com um prejuízo de $12 \frac{1}{2} \%$. Quanto custou o saco?

2) “É caro este chapéu por $\mathrm{Cr} \$ 38,00$ ", disse um comprador. "Eu ganho apenas 6\%", disse o vendedor. Qual o preço de custo do chapéu?

Fonte: Série Concórdia (1949, pp. 96-97).

O exemplo descrito no Quadro 8 propõe a determinação do preço de compra de uma mercadoria a partir do preço de venda e da taxa percentual de lucro na operação comercial. Na resolução, observa-se a relação inicial entre $\operatorname{Cr} \$ 120,00$ do preço de venda e Cr\$100,00 do preço de compra devido à taxa percentual de lucro de $20 \%$. Na continuidade, realiza-se a dedução da multiplicidade para a unidade e da unidade para a multiplicidade (preço de venda), valendo-se da divisão e da multiplicação como operações inversas, para determinação do preço de compra. Ainda são propostos problemas em diferentes contextos da realidade dos alunos e relacionados a operações de compra e de venda, com taxa percentual de lucro ou taxa percentual de prejuízo, para cálculo do preço original.

No Quadro 9, são explorados problemas envolvendo descontos em operações comerciais: 


\section{pro.posıções}

$e$-ISSN 1980-6248

\section{Quadro 9-Descontos}

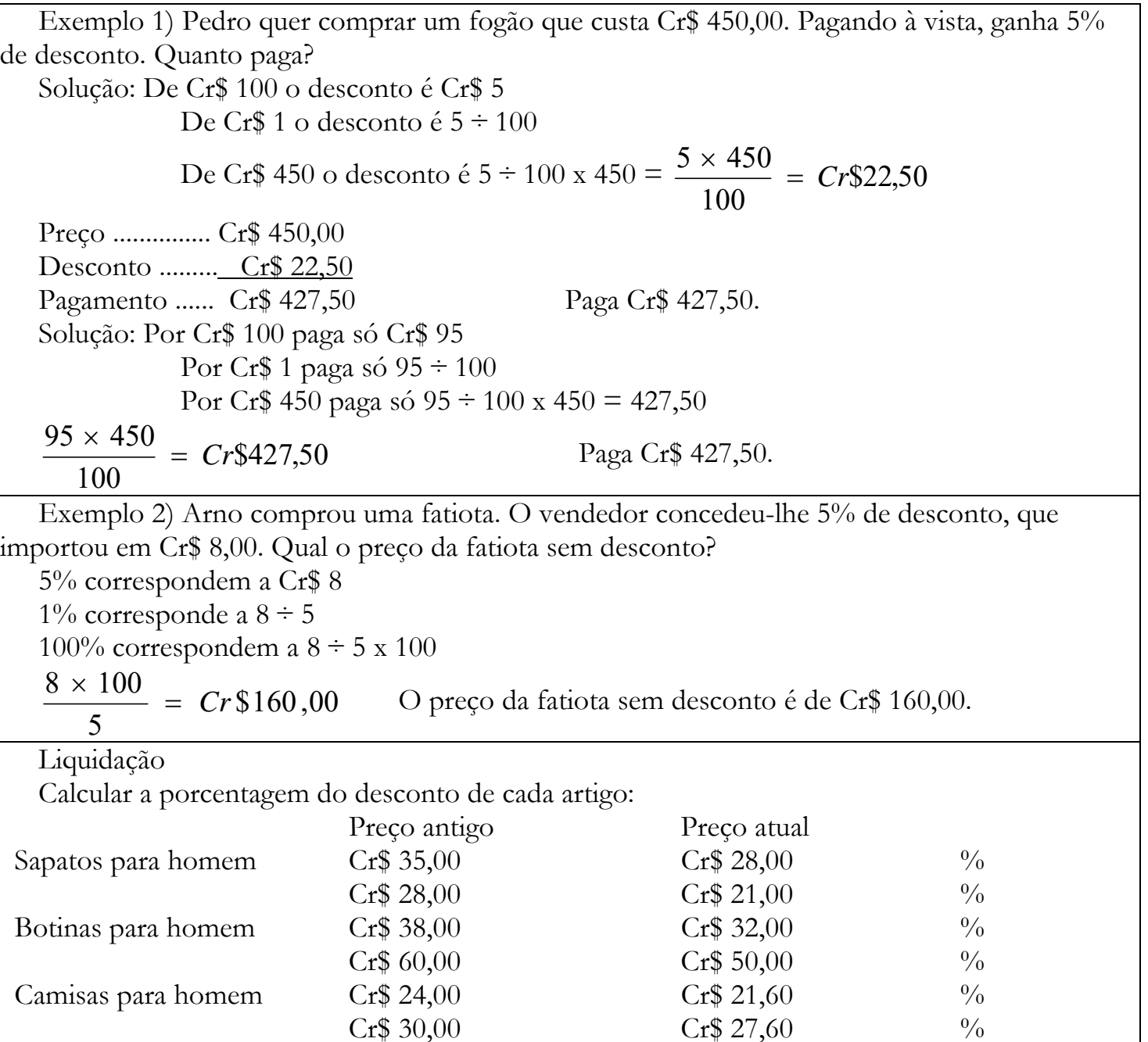

Fonte: Série Concórdia (1949, pp. 97-100).

No estudo de operações envolvendo descontos, observam-se exemplos em duas situações diferentes. No primeiro exemplo, o preço de custo do fogão e o percentual de desconto na compra à vista são conhecidos, sendo necessário calcular o preço pago após o desconto. Observa-se que na resolução são apresentadas duas possibilidades. Na primeira, calcula-se o valor do desconto a partir dos 5\%, desconta-se esse valor do preço de custo, obtendo-se o preço a pagar. $\mathrm{Na}$ segunda forma de resolução, considerando-se o desconto de $5 \%$ na compra à vista, paga-se $95 \%$ do preço de custo do fogão, calculando-se diretamente o preço a pagar a partir desse percentual. No segundo exemplo, sabem-se a taxa percentual de desconto e o valor correspondente ao desconto, sendo preciso determinar o preço da fatiota 


\section{pro.posições}

$e$-ISSN 1980-6248

http://dx.doi.org/10.1590/1980-6248-2016-0123

sem desconto, ou seja, o preço original. Ressalta-se que os dois exemplos, além de explorarem os conceitos de porcentagem, desenvolvem o pensamento proporcional com a dedução da multiplicidade para a unidade e da unidade para a multiplicidade. No Quadro 9, ainda se apresenta um exercício para cálculo da porcentagem de desconto em artigos masculinos que estão em liquidação, conhecendo-se o preço antigo e o preço de promoção. Acrescenta-se que, de acordo com Kreutz (1994), o processo pedagógico deveria partir sempre da realidade dos alunos, concorrendo para uma inserção mais efetiva deles nessa mesma realidade.

A sexta unidade de estudo da Terceira Aritmética da série Concórdia são os "juros". O estudo é introduzido por uma explanação teórica, com a definição de termos importantes da matemática financeira, utilizados nos cálculos envolvendo juros: capital (c), taxa (i), juro (j) e tempo ( $\mathrm{t}, \mathrm{d}$ ou $\mathrm{m})$. São usadas três simbologias diferentes para representar o tempo: $\mathrm{t}$ para o tempo em anos, $m$ para o tempo em meses e d para o tempo em dias. Destaca-se que a taxa é definida como o lucro de Cr $\$ 100,00$ em um ano, ideia essa aplicada no estudo da porcentagem nesta edição da Terceira Aritmética. Ressalta-se que, atualmente, a taxa de juros é definida como a porcentagem aplicada sobre a quantia emprestada por determinado tempo.

A Terceira Aritmética desenvolve separadamente o procedimento de cálculo do juro, da taxa, do capital e do tempo. No Quadro 10, apresenta-se a proposta de estudo para o cálculo do juro simples. 


\section{pro.posıções}

http://dx.doi.org/10.1590/1980-6248-2016-0123

\section{$e$-ISSN 1980-6248}

\section{Quadro 10 - Cálculo do juro}

Exemplo 1) Zeca tem um capital de Cr\$300,00 que deposita na Caixa Econômica. A Caixa paga $5 \%$ de juro ao ano. Em quanto importa o juro que Zeca recebe depois de 2 anos?

I. Solução racional

Cr\$ 100 em 1 ano rendem $\operatorname{Cr} \$ 5$ de juro

Cr\$ 1 em 1 ano rende $5 \div 100$

Cr $\$ 300$ em 1 ano rendem $5 \div 100 \times 300$

Cr $\$ 300$ em 2 anos rendem $5 \div 100 \times 300 \times 2=\frac{5 \times 300 \times 2}{100}=\operatorname{Cr} \$ 30,00$

II. Solução comercial

$j=\frac{c \times i \times t}{100}=\frac{300 \times 5 \times 2}{100}=\operatorname{Cr} \$ 30,00$

O juro que Zeca recebe depois de 2 anos é de $\operatorname{Cr} \$ 30,00$.

Exemplo 2) Calcular o juro de 5 meses de Cr $\$ 4.800$ a 31/2\%.

I. Solução racional

Cr\$ 100 em 12 meses rendem 3,5

Cr $\$ 1$ em 12 meses rende $3,5 \div 100$

Cr\$ 4.800 em 12 meses rendem $3,5 \div 100 \times 4800$

Cr $\$ 4.800$ em 1 mês rendem $3,5 \div 100 \times 4800 \div 12$

Cr $\$ 4.800$ em 5 meses rendem $3,5 \div 100 \times 4800 \div 12 \times 5=\frac{3,5 \times 4800 \times 5}{100 \times 12}=\operatorname{Cr} \$ 70$

II. Solução comercial

$$
j=\frac{c \times i \times m}{100 \times 12}=\frac{4800 \times 3,5 \times 5}{100 \times 12}=\operatorname{Cr} \$ 70,00
$$

Exemplo 3) Calcular o juro de 40 dias de Cr\$1.800,00 a 6\%.

I. Solução racional

Cr\$100 em 360 dias rendem $\mathrm{Cr} \$ 6$

Cr\$ 1 em 360 dias rende $6 \div 100$

Cr $\$ 1.800$ em 360 dias rendem $6 \div 100 \times 1800$

Cr $\$ 1.800$ em 1 dia rendem $6 \div 100 \times 1800 \div 360$

Cr $\$ 1.800$ em 40 dias rendem $6 \div 100 \times 1800 \div 360 \times 40=\frac{6 \times 1800 \times 40}{100 \times 360}=\operatorname{Cr} \$ 12$

II. Solução comercial

$$
j=\frac{c \times i \times d}{100 \times 360}=\frac{1800 \times 6 \times 40}{100 \times 360}=\operatorname{Cr} \$ 12,00
$$

1) Em 15 de março de 1936 o tio Lauro deposita na Caixa Econômica Cr\$ 450,00 à taxa de $5 \%$. A quanto sobe o seu dinheiro até 31 de dezembro do mesmo ano?

Fonte: Série Concórdia (1949, pp. 101-109).

Verifica-se que, no Quadro 10, estão descritos três exemplos com o cálculo do juro simples comercial, sendo que o exemplo 1 apresenta o tempo medido em anos, e os exemplos 2 e 3 trazem o tempo medido em meses e em dias, respectivamente. Nesses exemplos, o livro apresenta a solução racional e a solução comercial para o cálculo do juro simples. Na solução racional, inicialmente, observa-se a tomada da taxa percentual em relação a Cr\$100,00 para um período anual (1 ano, 12 meses ou 360 dias). Em seguida, realiza-se a dedução da multiplicidade 


\section{pro-posıções}

$e$-ISSN 1980-6248

http://dx.doi.org/10.1590/1980-6248-2016-0123

(Cr\$100,00) para a unidade (Cr\$1,00) e da unidade para a multiplicidade (capital), fazendo-se os cálculos proporcionais ao tempo de cada aplicação financeira. A solução comercial é feita por meio da expressão algébrica para cálculo do juro simples: $j=\frac{c \times i \times t}{100}$, observando-se que a variável t é substituída por m ou d, conforme o tempo está medido em meses ou em dias, havendo ainda a necessidade de transformações proporcionais no denominador da expressão algébrica (x 12 ou x 360), pois ela é definida para o tempo medido em anos.

No exemplo 2 e em exercícios propostos para cálculo do juro, verifica-se o uso de frações ordinárias ou de números mistos para representação de taxas percentuais não inteiras. O mesmo acontece na representação de períodos de tempo não inteiros. Junto com o cálculo do juro, o livro propõe o estudo da "cronologia" com a intenção de explorar o cálculo do juro simples exato, segundo se pode observar no problema 1 descrito no Quadro 10.

Nesta proposta de estudo se destaca o emprego da solução racional para o cálculo do juro, a qual é pouco usada na Educação Básica. Atualmente, predomina a solução comercial, pois a expressão algébrica para cálculo do juro simples, $j=\frac{c \times i \times t}{100}$, costuma ser utilizada nos anos finais do Ensino Fundamental, e a expressão $\mathrm{j}=\mathrm{c} \cdot \mathrm{i} \cdot \mathrm{t}$, geralmente, é empregada no Ensino Médio com a taxa percentual na forma unitária, como por exemplo, $\mathrm{i}=5 \%=\frac{5}{100}=0,05$.

Após desenvolver o cálculo do juro, a Terceira Aritmética sistematiza o cálculo da taxa no sistema de juro simples, como descrito no Quadro 11. 


\section{pro.posıções}

$e$-ISSN 1980-6248

\section{Quadro 11 - Cálculo da taxa}

Exemplo 1) Cr\$ 900,00 produziram em 1 ano $\operatorname{Cr} \$ 40,50$ de juro. A que taxa foi emprestado o capital?

Solução: Cr\$ 900 rendem em 1 ano 40,50

Cr\$ 1 rende em 1 ano 40,50 $\div 900$

Cr\$ 100 rendem em 1 ano 40,50 $\div 900 \times 100$

$\frac{40,50 \times 100}{900}=4,5=4 \frac{1}{2} \% \quad$ O capital foi emprestado a $4 \frac{1}{2} \%$.

Exemplo 2) Cr\$ 550,00 renderam em 144 dias Cr\$ 7,70 de juros. Qual foi a taxa?

Cr\$ 550 renderam em 144 dias $\mathrm{Cr} \$ 7,7$

Cr $\$ 1$ rendeu em 144 dias $7,7 \div 550$

Cr $\$ 100$ renderam em 144 dias $7,7 \div 550 \times 100$

Cr $\$ 100$ renderam em 1 dia $\quad 7,7 \div 550 \times 100 \div 144$

Cr\$ 100 renderam em 360 dias $7,7 \div 550 \times 100 \div 144 \times 360$

$\frac{7,7 \times 100 \times 360}{550 \times 144}=3,5=3 \frac{1}{2} \%$

A taxa é de $3 \frac{1}{2} \%$.

Fonte: Série Concórdia (1949, pp. 110-113).

Observa-se, no Quadro 11, que, no cálculo da taxa, o livro também enfatiza a resolução racional. Realiza-se a dedução da multiplicidade (capital) para a unidade (Cr\$1,00) e da unidade para a multiplicidade (Cr\$100,00), fazendo-se os cálculos proporcionais ao tempo de cada aplicação financeira. Registra-se que a taxa percentual é determinada em relação a Cr\$100,00 para um período anual, e representada por números mistos quando ela não for inteira. Os problemas propostos no livro exploram o cálculo da taxa com o tempo expresso em anos, em meses e em dias, considerando períodos comercias e períodos exatos.

No Quadro 12, desenvolve-se o cálculo do capital no sistema de juro simples, empregando-se a solução racional: 


\section{pro.posıções}

$e$-ISSN 1980-6248

\section{Quadro 12 - Cálculo do capital}

Exemplo 1) Que capital produzirá em 2 anos a 7\% Cr\$ 52,50 de juros?

Para render $\operatorname{Cr} \$ 7,00$ em 1 ano precisa-se de $\operatorname{Cr} \$ 100$

Para render Cr $\$ 1,00$ em 1 ano precisa-se de $100 \div 7$

Para render Cr\$52,00 em 1 ano precisa-se de $\quad 100 \div 7 \times 52,50$

Para render Cr $\$ 52,00$ em 2 anos precisa-se de $100 \div 7$ x 52,50 $\div 2$

$\frac{100 \times 52,50}{7 \times 2}=\operatorname{Cr} \$ 375,00 \quad$ O capital é de $\operatorname{Cr} \$ 375,00$.

Exemplo 2) Um freguês pagou uma fatura 3 meses depois do vencimento com Cr\$ 663,00. O negociante cobrou $8 \%$ ao ano para os 3 meses. Qual o valor da fatura?

Em 12 meses o juro é de Cr\$ 8

Em 1 mês o juro é de $\quad 8 \div 12$

Em 3 meses o juro é de $8 \div 12 \times 3=\frac{8 \times 3}{12}=\operatorname{Cr} \$ 2,00$

Cr\$ 102 provêm de Cr\$ 100

Cr\$ 1 provém de $\quad 100 \div 102$

Cr\$ 663 provêm de $100 \div 102 \times 663=\frac{100 \times 663}{102}=\operatorname{Cr} \$ 650,00$

O valor da fatura é de Cr\$650,00.

Fonte: Série Concórdia (1949, pp. 114-116).

No cálculo do capital do exemplo 1, conhecidos os juros da aplicação financeira, a proposta inicial do livro é deduzir o valor correspondente à taxa de juros anual sobre Cr\$100,00. Na continuidade, realiza-se a dedução da multiplicidade (juros sobre Cr $\$ 100,00$ ) para a unidade (Cr\$1,00), e da unidade para a multiplicidade (juros sobre o capital), fazendo-se os cálculos proporcionais ao tempo da aplicação financeira para determinar o capital.

Observa-se que no exemplo 2 se informa o montante da aplicação, e a dedução do valor inicial corresponde à taxa de juros anual sobre Cr\$100,00 somada com Cr\$100,00. Em seguida, propõe-se a dedução da multiplicidade (juros sobre $\operatorname{Cr} \$ 100,00+\operatorname{Cr} \$ 100,00)$ para a unidade (Cr\$1,00) e da unidade para a multiplicidade (juros sobre o montante), fazendo-se os cálculos proporcionais ao tempo da aplicação para encontrar o capital.

Ressalta-se que os problemas propostos no livro para cálculo do capital, considerando o período comercial ou o período exato, informam os juros ou o montante em diferentes contextos associados à realidade dos alunos das escolas paroquiais luteranas gaúchas.

A proposta de cálculo do tempo, na Terceira Aritmética, é apresentada no Quadro 13: 


\section{pro.posıções}

$e$-ISSN 1980-6248

\section{Quadro 13 - Cálculo do tempo}

Exemplo 1) Um capital de Cr\$2.500,00, emprestado a 8\%, rendeu Cr\$500,00 de juro. Por quanto tempo esteve empregado o capital?

Cr\$ 100 produzem Cr\$ 8 de juros em 1 ano

Cr\$ 1 produz Cr\$ 8 de juros em $1 \times 100$

Cr\$2.500 produzem Cr\$ 8 de juros em 1 x $100 \div 2500$

Cr\$2.500 produzem Cr\$ 1 de juros em 1 x $100 \div 2500 \div 8$

Cr\$2.500 produzem Cr\$500 de juros em $1 \times 100 \div 2500 \div 8$ x 500

$\frac{100 \times 500}{2500 \times 8}=2^{1 / 2}$ anos $\quad$ O capital esteve empregado por $2^{1 / 2}$ anos.

Exemplo 2) Em quantos meses um capital de Cr\$2.700,00 emprestado a 5\%, produziu Cr\$

90,00 de juro?

Cr\$ 100 produzem Cr\$ 5 de juros em 12 meses

Cr\$ 1 produz Cr $\$ 5$ de juros em $100 \times 12$

Cr\$2.700 produzem Cr\$ 5 de juros em $100 \times 12 \div 2700$

Cr\$2.700 produzem Cr\$ 1 de juros em $100 \times 12 \div 2700 \div 5$

Cr\$ 2.700 produzem Cr\$ 90 de juros em $100 \times 12 \div 2700 \div 5 \times 90$

$\frac{100 \times 12 \times 90}{2700 \times 5}=8$ meses $\quad$ O capital esteve empregado durante 8 meses.

Exemplo 3) Em quantos dias um capital de Cr\$ 9.600,00, emprestado a 4\%, produzirá Cr\$

179,20 de juros?

100 produzem 4,00 de juros em 360 dias

1 produz 4,00 de juros em $100 \times 360$

9.600 produzem 4,00 de juros em $100 \times 360 \div 9600$

9.600 produzem 1,00 de juros em $100 \times 360 \div 9600 \div 4$

9.600 produzem 179,20 de juros em $100 \times 360 \div 9600 \div 4 \times 179,20$

$\frac{360 \times 100 \times 179,20}{9600 \times 4}=168 \mathrm{dias}$

O capital esteve empregado durante 168 dias.

Fonte: Série Concórdia (1949, pp. 118-120).

No cálculo do tempo no sistema de juro simples são propostos três exemplos, com o tempo medido em anos, em meses e em dias, respectivamente, de acordo com o observado no Quadro 13. Na resolução pela forma racional, observa-se a tomada da taxa percentual em relação a Cr\$ 100,00 para um período anual (1 ano, 12 meses ou 360 dias). Na continuidade, realiza-se a dedução da multiplicidade (Cr\$100,00) para a unidade $(\operatorname{Cr} \$ 1,00)$, e da unidade para a multiplicidade (capital), fazendo-se os cálculos proporcionais ao tempo de cada aplicação financeira. Os problemas propostos exploram o cálculo do tempo considerando períodos comerciais e períodos exatos, utilizando-se a representação da taxa de juros e do tempo com números mistos. De acordo com Rambo (1994), lidando diariamente com dinheiro, inclusive com empréstimos na rede de agências das caixas rurais, exigia-se habilitação no manejo do cálculo de juros para o futuro agricultor. 


\section{pro.posıções}

$e$-ISSN 1980-6248

No Quadro 14, apresenta-se a proposta de estudo para a regra de companhia ou regra de sociedade na Terceira Aritmética. Ressalta-se que, na atualidade, esse conteúdo é pouco explorado na Educação Básica.

\section{Quadro 14 - Regra de companhia ou regra de sociedade}

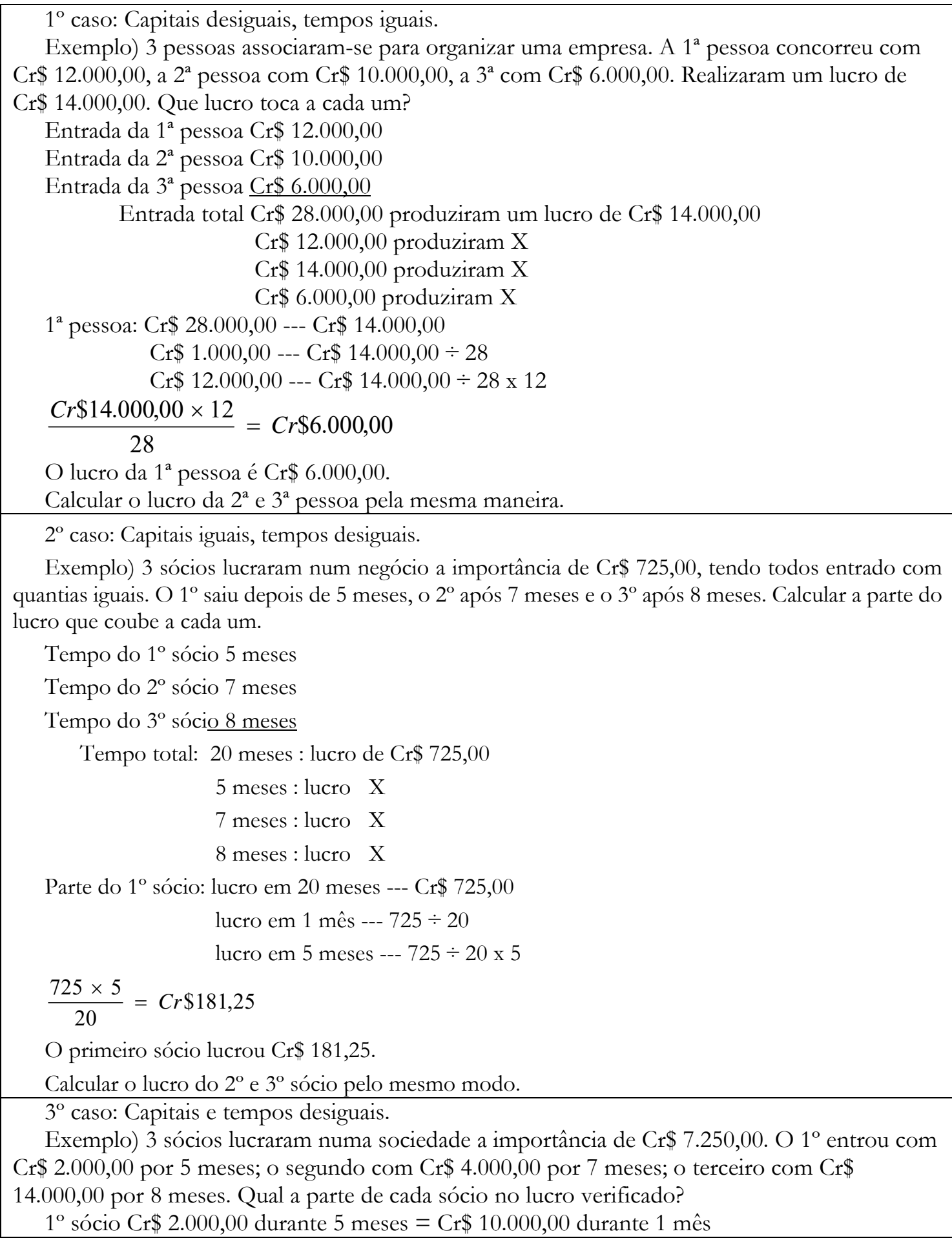




\section{pro.posições}

$e$-ISSN 1980-6248

http://dx.doi.org/10.1590/1980-6248-2016-0123

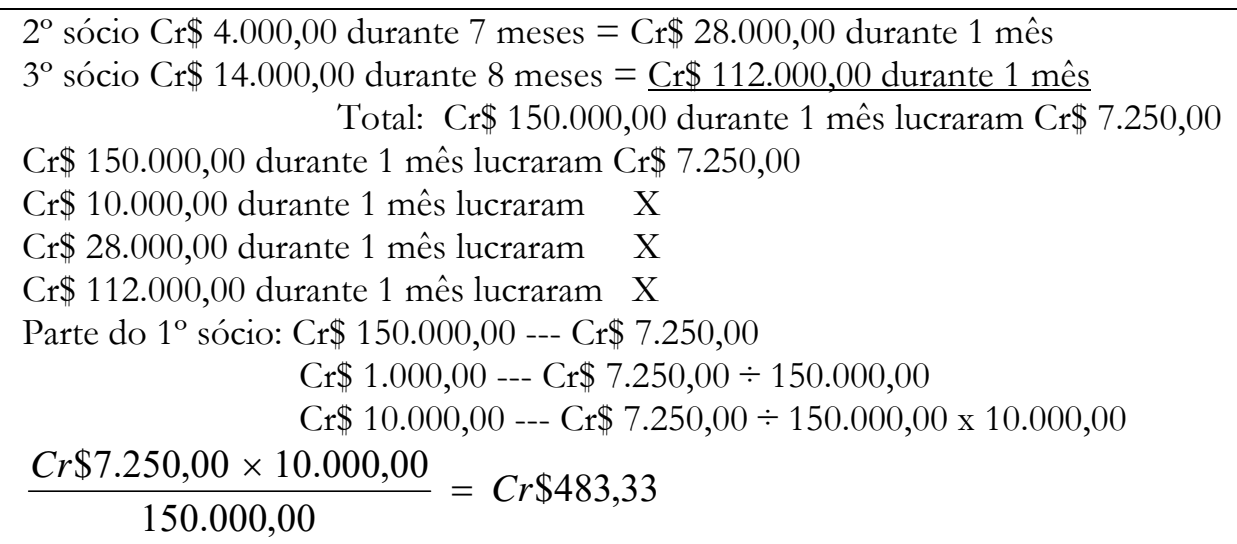

No estudo da regra de companhia são apresentados três casos, como descrito no Quadro 14. No primeiro caso, em que os capitais são desiguais e os tempos iguais, inicialmente se determina a soma dos capitais que produzem o lucro total. Em seguida, realiza-se a dedução da multiplicidade (capital total) para a unidade e da unidade para a multiplicidade (capital correspondente ao primeiro sócio), valendo-se da divisão e da multiplicação como operações inversas. Esse procedimento é repetido para determinação do lucro de cada integrante da sociedade. Observa-se que, no primeiro caso, os lucros são proporcionais aos capitais investidos.

No segundo caso, em que os capitais são iguais e os tempos desiguais, inicialmente se determina a soma dos tempos que geram o lucro total. Continua-se fazendo a dedução da multiplicidade (tempo total) para a unidade, e da unidade para a multiplicidade (tempo correspondente ao primeiro sócio), valendo-se da divisão e da multiplicação como operações inversas. Esse procedimento também é repetido para determinação do lucro de cada integrante da sociedade. Verifica-se que, no segundo caso, os lucros são proporcionais aos tempos de investimento.

No terceiro caso apresentado, os capitais e os tempos são desiguais. $\mathrm{Na}$ resolução do exemplo, inicialmente, determina-se o produto dos capitais investimentos pelos tempos de investimento, obtendo-se o capital total na unidade de tempo que produz o lucro total. Em seguida, realiza-se a dedução da multiplicidade (capital total na unidade de tempo) para a unidade, e da unidade para a multiplicidade (capital total correspondente ao primeiro sócio), valendo-se da divisão e da multiplicação como operações inversas. Para determinação do lucro 


\section{pro.posições}

$e$-ISSN 1980-6248

http://dx.doi.org/10.1590/1980-6248-2016-0123

de cada integrante da sociedade, se realiza o mesmo procedimento. Observa-se que, neste terceiro caso, os lucros correspondem proporcionalmente aos produtos dos capitais investidos e dos tempos de investimento. Ressalta-se que, nos três casos, a soma dos lucros correspondentes a cada sócio deve resultar no lucro total da sociedade.

Na edição da Terceira Aritmética da série Concórdia também se encontraram exercícios para preenchimento de faturas, variando a quantidade de mercadorias e os respectivos preços, de documentos de dívidas, de notas promissórias e de duplicatas, mudando-se nomes, importâncias e datas. Segundo Rambo (1994), a familiaridade e o manejo do cálculo, ao menos até o nível de juros, da regra de três e outros, representavam o mínimo de ferramental, indispensável para a solução dos múltiplos problemas do dia a dia das gerações de colonos.

Ressalta-se que esta abordagem da matemática comercial e financeira era proposta para os primeiros cinco anos da escolarização primária nas escolas paroquiais luteranas gaúchas e que, atualmente, esses conhecimentos matemáticos são desenvolvidos a partir dos anos finais do Ensino Fundamental.

\section{Considerações finais}

Tendo por base os referenciais da história cultural e da análise de conteúdo, investigouse o ensino da matemática comercial e financeira nas escolas paroquiais luteranas do RS, analisando-se as edições da Segunda Aritmética e da Terceira Aritmética da série Concórdia, editadas pela IELB para suas escolas, na primeira metade do século XX.

Com a análise realizada, observou-se que a abordagem da matemática comercial e financeira aconteceu através do estudo de operações comerciais de compra e de venda, de porcentagem comercial, de juros simples, de regra de companhia ou regra de sociedade e de documentos fiscais (notas fiscais, faturas, duplicatas e notas promissórias). Predominaram propostas de ensino contextualizadas com a realidade dos alunos das escolas paroquiais luteranas, incentivando-se o desenvolvimento do pensamento proporcional e do pensamento percentual em operações comerciais com lucro ou com prejuízo, explorando-se também o cálculo correto de troco e de dívidas e, em aplicações financeiras, envolvendo juros simples. 


\section{pro.posıções}

$e$-ISSN 1980-6248

http://dx.doi.org/10.1590/1980-6248-2016-0123

O estudo da porcentagem comercial aconteceu em diferentes contextos relacionados com: peso bruto, tara e peso líquido; lucros e perdas; compras e vendas; descontos. Nos exemplos, nos exercícios e nos problemas analisados sobre porcentagem comercial, se verificou que a taxa percentual é determinada em relação a Cr\$100,00, explorando-se o pensamento proporcional com a dedução da multiplicidade para a unidade e da unidade para a multiplicidade, valendo-se da divisão e da multiplicação como operações inversas.

Nos cálculos do juro simples se observou a solução racional e a solução comercial. A solução racional é o procedimento de cálculo utilizado na porcentagem comercial e o desenvolvimento do pensamento proporcional. O livro explorou este procedimento no cálculo do juro, da taxa, do capital e do tempo. A solução comercial é desenvolvida através da expressão algébrica para cálculo do juro simples: $j=\frac{c \times i \times t}{100}$, observando-se que a variável $\mathrm{t}$ é substituída por m ou d, conforme o tempo está medido em meses ou em dias. Verificaram-se problemas sobre juro simples, envolvendo períodos comerciais e períodos exatos e com o emprego de números mistos ou de frações ordinárias na representação de taxas de juros e do tempo, predominando a aplicação da solução racional. Ressalta-se que, atualmente, na Educação Básica predomina a solução algébrica sobre a solução racional no estudo dos juros simples, o que deixa de ser mais uma oportunidade para o desenvolvimento do pensamento proporcional.

No estudo da regra de companhia ou regra de sociedade, um conteúdo pouco desenvolvido na Educação Básica atualmente, o pensamento proporcional foi explorado nos três casos: capitais desiguais e tempos iguais (os lucros são proporcionais aos capitais investidos); capitais iguais e tempos desiguais (os lucros são proporcionais aos tempos de investimento); capitais e tempos desiguais (os lucros correspondem proporcionalmente aos produtos dos capitais investidos e dos tempos de investimento).

A análise das aritméticas da série Concórdia, direcionada para as escolas paroquiais luteranas gaúchas, na primeira metade do século XX, permitiu um adentramento na cultura escolar num lugar e num tempo determinados, identificando a abordagem da matemática comercial e financeira nesse contexto, contribuindo para a história da Educação Matemática e provocando uma reflexão sobre a atual forma de ensino desses conteúdos nas escolas de Educação Básica. 


\section{pro.posıções}

$e$-ISSN 1980-6248

http://dx.doi.org/10.1590/1980-6248-2016-0123

\section{Referências}

Arendt, I. C. (2005). Representações de germanidade, escola e professor no Allgemeine Lehrerz̧eitung Für Rio Grande do Sul [Jornal Geral para o Professor no Rio Grande do Sul]. Tese de Doutorado, Universidade do Vale do Rio dos Sinos, São Leopoldo, RS, Brasil.

Bardin, L. (2011). Análise de conteúdo. (L. A. Reto, \& A. Pinheiro, trads., obra original publicada em 1977). São Paulo: Edições 70, Martins Fontes.

Chartier, R. (1990). A bistória cultural: entre práticas e representações. Lisboa: Difel.

Chervel, A. (1990). História das disciplinas escolares - reflexões sobre um campo de pesquisa. Teoria \& Educação, (2), 177-229.

Dreher, M. N. (1999, julho/dezembro). O desenvolvimento econômico do Vale do Rio dos Sinos. Estudos Leopoldenses - Série História, 3(2), 49-70.

Julia, D. (2001, janeiro/junho). A cultura escolar como objeto histórico. Revista Brasileira de História da Educação, (1), 9-43.

Kreutz, L. (1991). O professor paroquial: magistério e imigração alemã. Porto Alegre: Ed. da UFRGS; Caxias do Sul: EDUCS.

Kreutz, L. (1994). Material didático e curriculo na escola teuto-brasileira. São Leopoldo: Ed. UNISINOS.

Kreutz, L. (2008, janeiro/abril). Livros escolares e imprensa educacional periódica dos imigrantes alemães no Rio Grande do Sul, Brasil 1870-1939. Revista Educação em Questão, 31(17), 24-52.

Kreutz, L., \& Arendt, I. C. (Org.). (2007). Livros escolares das escolas de imigração alemã no Brasil (1832-1940). Acervo documental e de pesquisa, Biblioteca UNISINOS, São Leopoldo, RS, 3 CD-ROM.

Kuhn, M. C. (2015). O ensino da matemática nas escolas evangélicas luteranas do Rio Grande do Sul durante a primeira metade do século XX. Tese de Doutorado, Universidade Luterana do Brasil, Canoas, RS, Brasil.

Lemke, M. D. (2001). Os princípios da educação cristã luterana e a gestão de escolas confessionárias no contexto das ideias pedagógicas no sul do Brasil (1824 - 1997). Canoas: Ed. ULBRA. 


\section{pro.posições}

$e$-ISSN 1980-6248

Lindemann, J. C. W. (1888). Amerikanisch-Lutherische Schul-Praxis (2a ed.). Sant Louis: Lutherischer Concordia - Verlag.

Mauro, S. (2005). Uma história da matemática escolar desenvolvida por comunidades de origem alemã no Rio Grande do Sul no final do século XIX e início do século XX. Tese de Doutorado, Universidade Estadual Paulista, Rio Claro, SP, Brasil.

Rambo, A. B. (1994). A escola comunitária tento-brasileira católica. São Leopoldo: Ed. UNISINOS.

Rambo, A. B. (1996). A escola comunitária tento-brasileira católica: a associação de professores e a escola normal. São Leopoldo: Ed. UNISINOS.

Roche, J. (1969). A colonização alemã e o Rio Grande do Sul (Vol. 1 e Vol. 2). Porto Alegre: Editora Globo.

Schubring, G. (2003, julho/dezembro). Relações culturais entre Alemanha e Brasil: "Imperialismo Cultural” versus "Nacionalização". Zetetiké ,11(20), 9-49.

Série Concórdia: Segunda Aritmética. (1948). Porto Alegre: Casa Publicadora Concórdia.

Série Concórdia: Terceira Aritmética. (1949). Porto Alegre: Casa Publicadora Concórdia.

Silva, C. M. S. (2014). Friedrich Bieri e a matemática para o ensino primário nas escolas teutobrasileiras. Anais do XI Seminário Temático - A constituição dos saberes elementares matemáticos: a aritmética, a geometria e o desenho no curso primário em perspectiva histórico-comparativa, 1890-1970, Florianópolis, SC, Brasil, 22.

Silva, C. M. S. (2015a). A aritmética de Matthäus Grimm no boletim informativo da associação de professores católicos da imigração alemã no Rio Grande do Sul. Anais do XII Seminário Temático - Saberes elementares matemáticos do ensino primário (1890 1970): o que dizem as revistas pedagógicas? (1890 - 1970), Curitiba, PR, Brasil, 16.

Silva, C. M. S. (2015b). A regra de ouro nos livros didáticos para escolas alemãs-brasileiras. Acta Scientiae, 17 (ed. especial), 41-59.

Sommer, A. (1984). Reminiscências da colônia teutônia: estrela décadas 20 e 30. São Leopoldo: Rotermund.

Unsere Schule. (1933-1935). Porto Alegre: Casa Publicadora Concórdia. 


\section{pro.posıções}

$e$-ISSN 1980-6248

http://dx.doi.org/10.1590/1980-6248-2016-0123

Wanderer, F. (2007). Escola e Matemática Escolar: mecanismos de regulação sobre sujeitos escolares de uma localidade rural de colonização alemã no Rio Grande do Sul. Tese de Doutorado, Universidade do Vale do Rio dos Sinos, São Leopoldo, RS, Brasil.

Warth, C. H. (1979). Crônicas da Igreja: fatos históricos da Igreja Evangélica Luterana do Brasil (1900 a 1974). Porto Alegre: Concórdia.

Weiduschadt, P. (2007). O Sínodo de Missouri e a educação pomerana em Pelotas e São Lourenço do Sul nas primeiras décadas do século XX: identidade e cultura escolar. Dissertação de Mestrado, Universidade Federal de Pelotas, Pelotas, RS, Brasil.

Weiduschadt, P. (2012). A revista "O Pequeno Luterano" e a formação educativa religiosa luterana no contexto pomerano em Pelotas - RS (1931-1966). Tese de Doutorado, Universidade do Vale do Rio dos Sinos, São Leopoldo, RS, Brasil.

Submetido à avaliação em 31 de março de 2016; aceito para publicaşão em 21 de dez̧embro de 2016. 